\title{
In vitro evaluation of dental bleaching effectiveness using hybrid lights activation
}

\author{
Avaliação in vitro da eficácia da fotoativação no clareamento \\ dental utilizando a técnica em consultório
}

\begin{abstract}
Purpose: The aim of this in vitro study was to evaluate whether using different types of light activation during the in-office bleaching agent technique increases the effectiveness of the dental bleaching procedure by measuring the color change in teeth.

Methods: From 60 extracted bovine incisor teeth, specimen sizes were standardized and dentin was conditioned by immersion in 38\% phosphoric acid for $15 \mathrm{~s}$. Following this procedure, the samples were placed in a water bath with ultrasound for 20 min and then immersed in a $25 \%$ coffee solution for a two-week period. The dentin was polished with a felt disc and aluminum oxide paste and finally sealed with colorless nail polish. Specimens were randomly divided into five groups, and their original color was measured using the EasyShade (VITA) spectrophotometer. All specimens received three applications of the bleaching agent Opalescence Xtra-Boost (Ultradent) during a period of 15 min each. Group 1 did not receive light activation, Group 2 was activated with a Halogen light (15 min), Group 3 was activated with a blue hybrid LEDs and a laser (15 min), Group 4 was activated with light from a green LED and a laser (15 min) and Group 5 was activated with a red laser (15 min). Tooth color was measured again after performing the various bleaching techniques on all specimens. The resulting data on color variations $\triangle E, \Delta a^{*}, \Delta b^{*}$ and $\Delta L^{*}$, and the color variations referenced on the Vita Classical scale were subjected to ANOVA, Tukey and Dunn tests $(\alpha=5 \%)$.

Results: The bleaching performance of $38 \%$ hydrogen peroxide was affected by the light source used; color reduction was observed for the blue LED and halogen lights, and quantitative assessments of tooth color measured by spectrophotometer and matched to the Vita Classical color scale arrived at similar results in all experimental groups.
\end{abstract}

Conclusions: The type of hybrid lights used interferes in the efficiency of the bleaching agent. Key words: Bleaching; light; LED

\section{Resumo}

Objetivo: Avaliar se fontes de luz aumentam a eficácia do peróxido de hidrogênio na técnica de clareamento profissional.

Metodologia: Foram empregados 60 dentes incisivos bovinos, com dimensões coronárias e radiculares padronizadas a partir do limite amelo-cementário, sendo descartada a porção lingual. Os corpos-de-prova (cp) foram limpos em ultra-som por 20 min e a dentina condicionada com $\mathrm{H}_{3} \mathrm{PO}_{4}$ a $38 \%$ por $15 \mathrm{~s}$, sendo os (cp) imersos em solução de café solúvel a $25 \%$ por duas semanas. A dentina foi impermeabilizada com esmalte e os (cp) divididos em 5 grupos, sendo a cor inicial mensurada através do espectofotômetro-EasyShade (VITA). Todos os (cp) receberam três aplicações por 10 min do gel clareador Opalescence Xtra-Boost (Ultradent) conforme segue: Grupo 1 - controle, não recebeu fotoativação, Grupo 2 - ativado com luz halôgena, Grupo 3 - ativado com LED azul/LASER, Grupo 4 - ativado com LED verde/LASER e Grupo 5 - ativado com LED vermelho. Após o clareamento foi mensurada a variação de cor $\Delta \mathrm{E}, \Delta \mathrm{a}^{*}, \Delta \mathrm{b}^{*}$ e $\Delta \mathrm{L}^{*}$ e as referentes à escala de cor Vita Clássico. Os dados foram submetidos à análise de variância, teste de Tukey e de Dunn $(\alpha=5 \%)$.

Resultados: A diferença geral da cor foi reduzida quando se empregou LED Azul e Luz Halógena, sendo que o desempenho do peróxido de hidrogênio a 38\% foi intensificado dependendo da fonte de luz utilizada. A avaliação quantitativa de cor, obtida por espectrofotômetro e pela escala de cor Vita Clássico, foram coincidentes.

Conclusão: $O$ tipo de fonte de luz empregada interfere na eficácia do agente clareador.

Palavras-chave: Clareamento dental; fotoativação; diodos emissores de luz

\section{Rodrigo Maximo Araújo a Carlos Rocha Gomes Torres a Maria Amélia Maximo de Araújo a}

a Postgraduate Program of Restorative Dentistry, Faculty of Dentistry of São José dos Campos, UNESP, São José dos Campos, SP, Brazil

\author{
Correspondence: \\ Maria Amélia Maximo de Araújo \\ R. Jorge de Oliveira Coutinho, $440-121$ \\ São José dos Campos, SP - Brazil \\ 12246-060 \\ E-mail: maximo@fosjc.unesp.br
}

Received: June 22, 2009

Accepted: November 24, 2009

Conflict of Interest Statement: The authors state that there are no financial and personal conflicts of interest that could have inappropriately influenced their work.

Copyright: (C) 2010 Araújo et al.; licensee EDIPUCRS. This is an Open Access article distributed under the terms of the Creative Commons AttributionNoncommercial-No Derivative Works 3.0 Unported License. 


\section{Introduction}

The smile is considered by many to be indispensable for communication, and many people's craving for white teeth has induced dentists to seek solutions that satisfy patients' expectations for an aesthetically pleasing smile. Dental bleaching stands out among these various aesthetic treatments. Involving a procedure that is minimally invasive, easy to accomplish, and low cost, dental bleaching can lead to results that satisfy the expectations of both patients and professionals.

With recent developments in bleaching techniques, auxiliary apparatuses have entered the market with the promise of making bleaching technique more efficient. However, there are doubts among professionals about the necessity and purpose of using these apparatuses to activate bleaching agents, and questions remain about which ones should be used in order to amplify the efficiency of the process without causing tooth, periodontium and pulp injuries.

Bleaching-related tooth injuries have been evaluated in the literature and refer to superficial rugosity alterations (1), microhardness decreases (2), chemical composition alterations (3), superficial morphology $(2,4)$, tooth sensitivity (5) and increases in pulp temperature $(6,7)$. Although risks do exist, they do not necessarily counterindicate the use of these techniques, since the bleaching is executed by professionals who are well-qualified and informed about the techniques' use, both minimizing the risk of harmful effects (8) and treating any harm that does occur after the use of bleaching techniques.

Light sources, applied to catalyze the chemical reaction of free radical liberation, are responsible for the oxidation of more complex carbon chains (darker) into carbon chains with simpler bonds (lighter) and light sources are directly related to the associated caloric emission. Eldeniz et al. (10), comparing temperature increases between different sources, demonstrated that the Dido Laser increases the temperature in the reaction by $11.7^{\circ} \mathrm{C}$, and the LED increases temperature by $6^{\circ} \mathrm{C}$. These two devices represent the extreme numbers found in the study, which found no statistically significant difference between the different types of equipment.

Wetter et al. (10) concluded that the combination of Whiteness HP and light from a laser yielded results that were significantly more effective compared to either the LED-HP Whiteness combination or the bleaching agent applied alone. Dostalova et al. (11) a 5-min decrease in bleaching time, which is significant, with the LED having a slight advantage because it uses less energy. Luk et al. (8) concluded that when bleaching gel and light sources are applied, the efficiency of the bleaching procedure increases, but the temperature inside and on the surface of the tooth increases as well.

In order to optimize the benefits of light activation, pigments with beta carotene, urucum (B. orellana) and others are added to the bleaching products to absorb the specific wavelength emitted by the device, reducing the non-absorbed quantity of energy and augmenting the device's efficiency (12).
To test our hypothesis regarding whether different light sources increase the efficiency of a bleaching gel, we used spectrophotometers to evaluate the effects of the $38 \%$ hydrogen peroxide activation in association with the following light sources: halogen lamp photopolymerizer, blue hybrid LED devices/infrared LASER, green LED/ infrared LASER and red LASER. The effects of these different techniques were assessed according to the general color variation of the specimen when the professional bleaching technique was applied.

\section{Methodology}

Sixty recently extracted bovine incisor teeth, healthy and erupted, were obtained from animals with an average age of three years. These teeth were extracted and cleaned with scalpel blades, and their coronary and radicular dimensions were measured at the amelo-cement junction. After measurement, perpendicular cuttings were made at the incisal and apical regions. The lingual portion of each tooth was removed using a lengthwise cutting, the specimen was treated to prophylaxis with a sodium bicarbonate jet (Profi II-Daby-Atlante, Ribeirão Preto, SP, Brazil) to remove extrinsic stains, and the exposed dentin was then conditioned with $38 \% \mathrm{H}_{3} \mathrm{PO}_{4}$ for $15 \mathrm{~s}$.

The method used to darken the teeth consisted of an adaptation one of the method described by Suliemam et al. (13). Next, the teeth were immersed in $200 \mathrm{ml}$ of a newly prepared coffee solution (Nescafé - Nestlé, Caçapava, Brazil) with a concentration of $25 \%$ (weight per volume) and kept below $37^{\circ} \mathrm{C}$ in a bacteriological greenhouse for 15 days. The solution was shaken every day and changed after the first seven days. After this period, the enamel surfaces were polished with aluminum oxide paste (SDI Limited, Bayswater, Victoria, Australia) using a felt disc.

For waterproofing and patterning, the sixty specimens each received two layers of colorless nail polish (Colorama, Maybelline, São Paulo, SP, Brazil) on the exposed dentin layer, guaranteeing that any penetration by the bleaching agent would occur exclusively through the vestibular surface of the enamel. Colorless nail polish was also applied to the vestibular surface of the teeth in order to isolate a preselected area of the dental enamel. To pattern this color-gauging area, a circular paper disc with a 7-mm diameter was placed on the vestibular surface before the nail polish application and removed once the nail polish had dried. Next, the specimens were randomly separated into five groups with twelve specimens in each.

In order to measure tooth color, we used a model called CIE $\mathbf{L}^{*} \mathbf{a}^{*} \mathbf{b}^{*}$, which is a mathematical system for describing the three dimensions of color perceptible to human eyes (red, green and blue). This approach is considered an international model for measuring color. The model CIE $\mathbf{L} * \mathbf{a} * \mathbf{b} *$ represents a tridimensional color space with three axes: $\mathbf{L}, \mathbf{a}$, and $\mathbf{b}$. The letter $\mathbf{L}^{*}$ represents the measure of luminosity or clarity of an object, and it is quantified according to a scale on which the perfect black has a value 
of $\mathbf{L}^{*}$ equal to zero, whereas the total white has a value of $\mathbf{L} *$ equal to 100 . There are also two chromatic components, which represent variations in hue and chroma. The a* axis is measured from red ( $\mathbf{a}^{*}$ positive) to green (a* negative), varying, respectively, from +120 to -120 . The $\mathbf{b}^{*}$ axis is measured from yellow ( $\mathbf{b}^{*}$ positive) to blue ( $\mathbf{b} *$ negative), varying, respectively, from +120 to -120 . The coordinates $\mathbf{a} *$ and $\mathbf{b} *$ approach zero for neutral colors (white, gray) and increase in magnitude for more saturated and intense colors. This system enables both the numerical definition of a color and the calculation of differences between two colors $(14,15)$.

To evaluate the color alteration of the teeth, we used an intraoral dental spectrophotometer, Vita EasyShade ${ }^{\circledR}$ (VITAZahnfabrik H. Rauter Gmbh \& Co. KG, Bad Säckingen, Germany). Used immediately after the darkening of the teeth and again after the completion of bleaching procedures, the spectrophotometer helped us to obtain values for $\mathrm{L}^{*}$, $\mathrm{a}^{*}$ and $\mathrm{b}^{*}$, and it also measured tooth color in comparison to positions on the Vita Classical scale. The bleaching gel utilized for all the specimens was the $38 \%$ hydrogen peroxide Opalescence Xtra Boost (Ultradent, South Jordan, UT, USA), spread in a layer $\pm 2 \mathrm{~mm}$ thick. Next, we will describe the bleach application procedures for each group and the low power light sources:

Group 1 - (control group without light activation) Bleaching agents were applied for $15 \mathrm{~min}$, shaking every 3 min for bubble displacement. During this time, the first application of gel was removed with a suction tip, the tooth was aired out, and these steps were repeated twice more, for a total of three gel applications and removals with water/air spray. During the exposure period, the teeth were protected from ambient light.

Group 2 - (halogen light) The procedures used for the second group were identical to the ones used for the control group, except that along with each application we applied a photoactivation scheme with a photopolymerizer device with a halogen light XL 3000 (3M-ESPE, St. Paul, MN, USA) with power density of $600 \mathrm{~mW} / \mathrm{cm}^{2}$, as described later on. The bleaching agent was applied, with activation for $1 \mathrm{~min}$, shaking and waiting 1 more min, and reactivation for $1 \mathrm{~min}$. This step was repeated seven more times, totaling 15 min of application. The bleaching agent was removed with a suction tip; then, these steps were repeated two more times.

Group 3 - (blue LED/LASER) Following the application and activation schemes used for Group 2, for Group 3, our light source was the EASY BLEACH device (CLEAN LINE, Taubaté, SP, Brazil) fitted with two blue LEDs with a wavelength range of $670 \mathrm{\eta m}$ and power of $500 \mathrm{~mW}$, combined with a low-intensity infrared laser that emitted energy with a wavelength range of $795 \mathrm{\eta m}$ and power of $120 \mathrm{~mJ}$.

Group 4 - (green LED/LASER) Again following the application and activation schemes of Group 2, we used the EASY GREEN device (CLEAN LINE, Taubaté, SP, Brazil) fitted with two green LEDs with a wavelength range of $530 \mathrm{\eta m}$ and power of $500 \mathrm{~mW}$, alongside a low-intensity infrared laser that emitted energy with a wavelength range of $795 \eta \mathrm{m}$ and power of $120 \mathrm{~mJ}$.

Group 5 - (red LASER) The final group utilized the same application and activation schemes of the previous groups, but activated the reaction using a red laser (CLEAN LINE, Taubaté, SP, Brazil) fitted with three laser diodes of $50 \mathrm{~mW}$ each, emitting red light with a wavelength range of $660 \eta \mathrm{m}$.

After the end of the bleaching process for the different groups, the color of the teeth was again evaluated. For each specimen, we calculated the variation of the values as $(\Delta)$ of $L^{*}, a^{*}$ and $b^{*}$, subtracting the value found after the bleaching from the value measured in the darkened (pretreatment) tooth. Then, we calculated the variation in color composition or total variation of color, designated with the acronym $\Delta \mathrm{E}^{*} \mathrm{ab}$, using the following formula:

$$
\Delta E^{*} \mathbf{a b}=\left[\left(\Delta \mathbf{L}^{*}\right)^{2}+\left(\Delta \mathbf{a}^{*}\right)^{2}+\left(\Delta \mathbf{b}^{*}\right)^{2}\right]^{0.5}
$$

\section{Statistical Analysis}

In order to determine each tooth's color, we obtained the values of $\mathrm{L}^{*}, \mathrm{a}^{*}$ and $\mathrm{b}^{*}$ for the teeth using spectrophotometers and the general difference of color $(\Delta \mathrm{E})$. In order to calculate the variation between specimens according to the Vita Classical scale, the recorded values were ordered in scores from 1 to 6 in a luminosity sequence, with 1 representing the lightest specimens and 6 representing the darkest, according to Fig. 1.

For each specimen, the score of the darkened tooth was subtracted from its score recorded after bleaching. In this way, we determined the placement of the color of each tooth on the Vita Classical scale. To analyze the data, the analysis of variance test (ANOVA) was applied, followed by the Tukey test, and for the calculation of the variation of color scores according to Vita Classical scale, we used the non-parametric Kruskall-Wallis test, followed by the Dunn multiple comparison test. In all of these analyses, we established a significance level of $5 \%$.

\begin{tabular}{|l|c|c|c|c|c|c|c|c|c|c|c|c|c|c|c|c|}
\hline Scale & B1 & A1 & B2 & D1 & A2 & D2 & C2 & D3 & A3 & D4 & B3 & A3.5 & B4 & C4 & A4 & C4 \\
\hline Score & 1 & 2 & 3 & 4 & 5 & 6 & 7 & 8 & 9 & 10 & 11 & 12 & 13 & 14 & 15 & 16 \\
\hline
\end{tabular}

Fig. 1. The order of the Vita scale according to luminosity, from the lightest to the darkest. 


\section{Results}

\section{A - Color comparison in the spectrophotometer}

Table 1 presents the variance analysis from the data that refers to $\triangle E$ from the CIEL*a*b* System, which resulted in an $\mathbf{F}$-test significant at the 5\% confidence level. In Figure 1, we provide a representative graphic of the means and standard deviations of $\Delta \mathbf{E}$ for each study group.

Next, the values for $\Delta \mathrm{a}^{*}, \Delta \mathrm{b}^{*}$ e $\Delta \mathrm{L}^{*}$ derived from CieLab were submitted to ANOVA separately. These are all important factors in estimating color changes: $\Delta \mathrm{L}^{*}$ is responsible for luminosity, varying from black to white, and $\Delta \mathrm{a}^{*}$ and $\Delta \mathrm{b}^{*}$ correspond to differences in chromaticity on the axes, varying from red to green and from yellow to blue, respectively. We conducted the ANOVA test on the $\Delta \mathbf{a}^{*}$ data and, in Tables 2 and 3 , verified that the $\mathbf{F}$-test was significant at the $5 \%$ level of confidence.

For the $\Delta \mathbf{L}$ calculation, corresponding to the difference in tooth luminosity before and after the whitening treatment, we also calculated the analysis of variance (ANOVA), not ascertaining an F-test significant difference.

Table 5 presents a visual compilation of the measurements and the respective homogeneous groups identified by the statistical analysis. There, we can see that the highest mean changes in tooth color always occurred with blue LED and halogen light sources, without any difference between them. In $\Delta \mathbf{E}$, teeth treated with the blue LED and the photopolymerizer with halogen light presented significantly higher color variation than teeth in the control group (not activated). The green LED and the red laser did not show any significant difference from the control group. In $\Delta \mathbf{a} *$, the group of teeth treated with the blue LED presented a significant reduction of chromaticity from red to green in relation to the other groups, including the control group. In $\Delta \mathbf{b} *$, we found no difference between the groups of teeth treated with halogen or blue LED light sources. However, these two groups significantly differed from all the other groups in their reduction in chromaticity from yellow to blue, not ascertaining any difference between these. In $\Delta \mathbf{L}^{*}$, we found no significant difference among the groups in relation to luminosity, even though the highest average numbers were found among the group of teeth treated with the blue LED lights. For this reason, the Tukey test was not applied.
Table 1. Analysis of Variance for the values of $\Delta E$.

\begin{tabular}{lcccc}
\hline Variation cause & GL & QM & F & P \\
\hline Light source & 4 & 84.22 & 7.31 & 0.0001 \\
Error & 55 & 11.52 & & \\
Total & 59 & & & \\
\hline
\end{tabular}

Table 2. Analysis of Variance for the values of $\Delta a^{*}$.

\begin{tabular}{lcccc}
\hline Variation cause & GL & QM & F & P \\
\hline Light source & 4 & 5.24 & 3.51 & 0.0127 \\
Error & 55 & 1.49 & & \\
Total & 59 & & & \\
\hline
\end{tabular}

Table 3. Analysis of Variance for the values of $\Delta b^{*}$.

\begin{tabular}{lcccc}
\hline Variation cause & GL & QM & F & P \\
\hline Light source & 4 & 68.46 & 13.4 & 0.0001 \\
Error & 55 & 5.10 & & \\
Total & 59 & & & \\
\hline
\end{tabular}

Table 4. Analysis of Variance for the values of $\Delta L^{*}$.

\begin{tabular}{lcccc}
\hline Variation cause & GL & QM & F & P \\
Light source & 4 & 19.92 & 1.68 & 0.17 \\
Error & 55 & 11.88 & & \\
Total & 59 & & & \\
\hline
\end{tabular}

\section{B - Color comparison in the Vita Classical scale}

The Kruskall-Wallis test was performed on the scores obtained for each of the groups. It showed a value of $P=0.0025$, which led us to reject the null hypothesis, indicating that there are differences among the groups. The results of the Dunn multiple comparison test can be seen in Table 6 .

As we see in Table 6, there were no significant differences between the group that activated the photopolymerizer with the halogen lamp and the group using the hybrid blue LED/ laser method. Yet, these groups presented a significantly wider range of variation in color scores than the control group did. The other devices that were tested did not present any performance-related difference when compared to the control group.

Table 5. Mean values obtained for $\Delta \mathrm{E}, \Delta \mathrm{a}^{*}, \Delta \mathrm{b}^{*}$ e and $\Delta \mathrm{L}^{*}$ with the respective homogeneous groups from the groups studied.

\begin{tabular}{lccccccc}
\hline \multicolumn{1}{c}{ Light source } & \multicolumn{2}{c}{ Mean $\Delta \mathrm{E}$} & \multicolumn{2}{c}{ Mean $\Delta \mathrm{a}$} & \multicolumn{2}{c}{ Mean $\Delta \mathrm{b}$} & \multicolumn{1}{c}{ Mean $\Delta \mathrm{L}$} \\
\hline Control & 5.39 & $\mathrm{C}$ & 1.65 & $\mathrm{AB}$ & 3.40 & $\mathrm{~B}$ & 3.44 \\
Blue LED & 10.71 & $\mathrm{~A}$ & 2.93 & $\mathrm{~A}$ & 6.94 & $\mathrm{~A}$ & 6.63 \\
Halogen & 10.08 & $\mathrm{AB}$ & 2.04 & $\mathrm{AB}$ & 7.51 & $\mathrm{~A}$ & 5.73 \\
Red Laser & 5.06 & $\mathrm{C}$ & 1.12 & $\mathrm{AB}$ & 1.86 & $\mathrm{~B}$ & 4.22 \\
Green LED & 6.62 & $\mathrm{BC}$ & 1.85 & $\mathrm{~B}$ & 4.24 & $\mathrm{~B}$ & \\
\hline
\end{tabular}

* Critical comparison value for the Tukey test $=2.60$. The means followed by the same letter do not differ. 
Table 6. Results of Dunn test (5\%).

\begin{tabular}{lccc}
\hline \multicolumn{1}{c}{ Groups } & Rank means & \multicolumn{2}{c}{ Homogeneous sets* } \\
\hline Control & 19.167 & $\mathrm{~A}$ & \\
Red LED & 22.167 & $\mathrm{~A}$ & $\mathrm{~B}$ \\
Green LED & 30.458 & $\mathrm{~A}$ & $\mathrm{~B}$ \\
Blue LED & 39.500 & & $\mathrm{~B}$ \\
Halogen & 41.208 & & $\mathrm{~B}$ \\
\hline
\end{tabular}

* The sets followed by the same letters do not differ significantly.

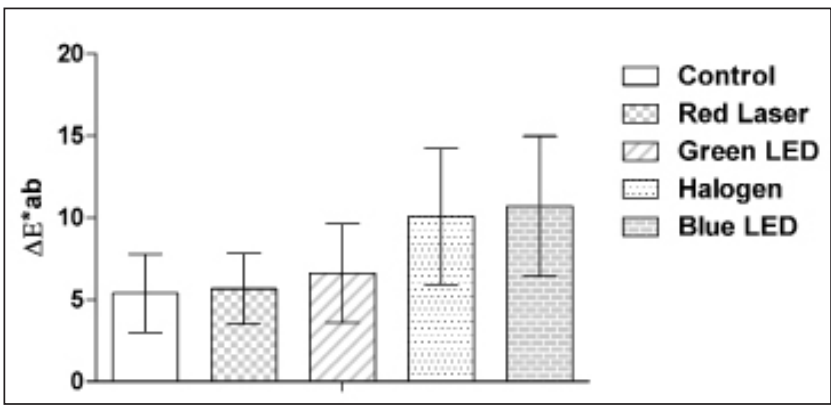

Fig. 2. Mean and standard deviation of $\triangle E$ in each study group.

\section{Discussion}

The hypothesis that light sources improve the efficiency of tooth-bleaching gel was tested by applying the CieL*a*b* system of values and delimiting an area on the medium third of the crown of the teeth that, according to Goodkind and Schwabacher (16), is the area of the tooth that is most representative in terms of color. The spectrophotometer probe was positioned at that location on each pigmented specimen to perform the initial and post-bleaching readings.

From the data we gathered, when the experimental groups were compared to one another using the general evaluation of color, $\Delta \mathrm{E}$, we found that the various experimental groups performed differently; the groups using $38 \%$ hydrogen peroxide and either blue LEDs or halogen lights, rendered the best bleaching performances, with means of 10.71 and 10.08 , respectively (Tables 1 and 2). Thus, we find that the ability of light activation to increase the efficiency of the bleaching agent depends on the light source being used. On the other hand, in the control group and in the groups treated with red and green lasers, the means were lower and the performances similar to one another. Reyto (17) writes about the use of lasers in combination with bleaching agents and affirms that this combination is ideal, with a minimum of harmful effects on teeth and strong results similar to those we obtained with blue LED/laser. However, other studies $(8,10,11)$ dissent with these claims. Buchalla and Attin (6) argue that light sources' potential to increase the efficacy of bleaching agents is limited because, while the light accelerates the process, it also produces heating. This heating can raise the intrapulpal temperature and increase the penetration of peroxide in the pulp, leading to oxidative stress with negative effects on cell metabolism.
The extent of the bleaching agent's penetration of the enamel significantly influences the color change of the teeth, as verified by Sulieman et al. (18), but this penetration of the dentin can lead to injuries to the dentin-pulp complex $(6,12)$. Buchalla and Attin (6) also refer to increases in sensitivity and to micro-morphological changes that may be intensified when these light sources are applied, although they lack evidence to prove this assertion. The temperature increase associated with light activation techniques is mentioned by some researchers (7-9,18), whereas Yazigi et al. (19) did not find any increase in temperature.

In order to observe differences in chromaticity along the axes $L^{*}, a^{*}$ and $b^{*}$ according to the CIELab system, we conducted an evaluation of the numerical values for each of the axes separately. This approach allowed us to verify whether the treatment led to changes in the luminosity of the teeth $\left(\Delta \mathrm{L}^{*}\right)$, or to alterations from red to green $\left(\Delta \mathrm{a}^{*}\right)$ or yellow to blue $\left(\Delta b^{*}\right)$. Within these analyses, we observed that the blue LED stood out from other groups as having the highest numerical values, reducing the reddish chroma of the teeth (Table 5), which was particularly significant in comparison to the green LED light source. Luo et al. (14) believe that the component $b^{*}$ is the most important indicator of bleaching, although any factor of CIELab can be considered in isolation. Concerning the reduction of the yellow chroma, we found that the highest mean color changes occurred within groups treated with either the blue LED or the halogen light, which were significantly different from the control group, red laser group, and the green laser group, among which there were no significant differences. Tavares et al. (20) also found that light activation reduced the yellow chroma of the teeth. Concerning the luminosity factor of the teeth when analyzing $\left(\Delta \mathrm{L}^{*}\right)$, the behavior of all study groups was similar; there were no significant differences among the study groups in this regard. In other words, the luminosity of the teeth did not depend on the light sources (or lack of light sources) utilized; even in the control group, where only the bleaching agent was used, the result stayed the same. We also observed that, despite the lack of significant differences in luminescence among the groups, the highest numerical values for this characteristic were to be found in the blue LED group, followed by the halogen light group.

These outcomes affirm the findings of other authors who likewise find evidence of an increase in $\mathrm{a}^{*}$ and $\mathrm{b}^{*}$ after dental bleaching (21), and they contrast with Ishikawa-Nagai et al. (15), who observed an increase in luminosity $L^{*}$. The alteration in luminosity represents how much the tooth lightened as a result of treatment, since this color dimension represents the amount of white incorporated to the hue.

When we proceeded to evaluate the results obtained by Easyshade in the Vita Classical scale, we observed that the blue LED and the halogen light yielded significant increases in dental bleaching effectiveness when compared with the control group (Table 6). These results agree with the results of the quantitative analysis of $\Delta \mathrm{E}^{*} \mathrm{ab}$, further demonstrating that the performance of the blue LED and 
halogen lights are certainly more effective in combination with the bleaching agent, Opalescence Xtra Boost. The results obtained with the blue LED and halogen lights may have occurred due to the presence of dyes in the bleaching gel. The light's color is determined by a specific wavelength, and because the objects do not have their own light intensity, their colors depend on the incident light, which is affected by such factors as objects' texture, light absorption, and reflection capacity. Color can be defined as additive (light source) or subtractive (pigment), whereas the incorporation of pigments in the bleaching gel will work to select a specific wavelength, absorbing more energy from the light source, and thereby catalyzing the chemical reaction more effectively. Observing the chromatic circle, we are able to identify the complementary colors, which are most able to absorb the discharged light of their opposing colors. For example, orange is complementary to blue; when we face an orange dye, orange is the only color being reflected, while other colors are absorbed in different degrees. The mostabsorbed color will be orange's complementary color, blue. By this logic, in order to intensify the absorption of the blue light emitted by the LED devices, bleaching gels with (orange) carotene dye should be used (12). Considering that the bleaching gel Opalescence Xtra Boost contains this dye, the results of our study are justified for both the blue LED and the halogen light, whose emissions are also blue.

The results obtained in this study lead us to deduce that the bleaching agent may have its performance intensified by light sources, although the efficacy of the light source also depends on the dye being used in each bleaching agent. We also showed that the application of each technique should be cautious, attending not only to fast outcomes of the bleaching process but also to the protection of the dentinpulp complex.

\section{Conclusions}

- According to the light source being used, the effects of $38 \%$ hydrogen peroxide may be intensified by light activation techniques;

- The general difference in color was significantly reduced when blue LED and halogen light were applied; and

- The quantitative evaluation of tooth color through the spectrophotometer and that same device's ranking of the tooth color according to the Vita Classical scale both identified similar results for the various study groups.

\section{References}

1. McGuckin RS, Babin JF, Meyer BJ. Alterations in human enamel surface morphology following vital bleaching. J Prosthet Dent 1992;68:754-60

2. Shannon H, Spencer P, Gross K, Tira D. Characterization of enamel exposed to $10 \%$ carbamide peroxide bleaching agents. Quintessence Int 1993;24:39-44.

3. McCraken MS, Haywood VB. Demineralization effects of $10 \%$ carbamide peroxide. J Dent 1996;24:395-8.

4. Araujo RM, Torres CR, Araújo MA. Influência dos agentes clareadores e um refrigerante à base de cola na microdureza do esmalte dental e a ação da saliva na superfície tratada. Rev Odonto Ciênc 2006;21:118-204.

5. Mokhlis GR, Matis BA, Cochran MA, Eckert GJ. A clinical evaluation of carbamide peroxide and hydrogen peroxide whitening agents during daytime use. J Am Dent Assoc 2000;131:1269-77.

6. Buchalla W, Attin T. External bleaching therapy with activation by heat, light or laser - a systematic review. Dent Mater 2007; 23:586-96.

7. Zhang C, Wang X, Kinoshita J, Zhao B, Toko T, Kimura Y, Masumoto $\mathrm{K}$ Effects of KTP laser irradiation, diode laser and LED on tooth bleaching: a comparative study. Photomed Laser Surg 2007 2007;25:91-5.

8. Luk K, Tam L, Hubert M. Effect of light energy on peroxide tooth bleaching. J Am Dent Assoc 2004;135:194-201;228-9.

9. Eldeniz AU, Usumez A, Usumez S, Ozturk N. Pulpal temperature rise during light-activated bleaching. J Biomed Mater Res B Appl Biomater 2005;72:254-9

10. Wetter NU, Barroso MC, Pelino JE. Dental bleaching efficacy with diode laser and LED irradiation: an in vitro study. Lasers Surg Med 2004;35:254-8.

11. Dostalova T, Jelinkova H, Housova D, Sulc J, Nemec M, Miyagi M, Brugnera Junior A, Zanin F. Diode laser-activated bleaching. Braz Dent J 2004;15:SI3-8.
12. Torres $C R$, Borges $A B$, Kubo CH, Gonçalves SE, Araújo RM, Celaschi $\mathrm{S}$ et al. Clareamento dental com fontes híbridas LED/Laser. São Paulo: Santos; 2007.

13. Sulieman M, Addy M, MacDonald E, Rees JS. The effect of hydrogen peroxide concentration on the outcome of tooth whitening: an in vitro study. J Dent 2004;32:295-9.

14. Luo W, Westhand S, Brunton P, Ellwood R, Prety IA, Mohan N. Comparison of the ability of different colour indices to assess changes in tooth whiteness. J Dent 2007;35:109-16.

15. Ishikawa-Nagai S, Terui T, Ishibashi K, Weber HP, Ferguson M. Comparison of effectiveness of two 10\% carbamide peroxide tooth-bleaching systems using spectrophotometric measurements. J Esthet Rest Dent 2004; 16:368-76.

16. Goodking RJ, Schwabacher, WB. Use of a fiber-optic colorimeter for in vivo color measurements of 2830 anterior teeth. J Prosthet Dent 1987;58:535-42.

17. Reyto R. Laser tooth whitening. J Esthet Dent 1998;42:7557-62.

18. Sulieman M, Addy M, MacDonald E, Rees JS. The bleaching depth of a $35 \%$ hydrogen peroxide based in-office product: a study in vitro. J Dent 2005;33:33-40.

19. Yazici AR, Khanbodaghi A, Kugel G. Effects of an in-office bleaching system (ZOOM) on pulp chamber temperature in vitro. J Contemp Dent Pract 2007;8:19-26.

20. Tavares M, Stultz J, Newman M; Smith V, Kent R, Carpino E, Goodson JM. Light augments tooth whitening with peroxide. J Am Dent Assoc 2003;134:167-75.

21. Cronin MJ, Charles CA, Zhao Q, Dembling WZ. Compararison of two over-the-counter tooth whitening products using a novel system. Compend Contin Educ Dent 2005;26:140-7. 